\title{
Synthesis of photocatalytic zinc oxide nanoflowers using Peltophorum pterocarpum pod extract and their characterization
}

\author{
Ramesh Vinayagam ${ }^{1} \cdot$ Shraddha Pai ${ }^{1} \cdot$ Gokulakrishnan Murugesan ${ }^{2} \cdot$ Thivaharan Varadavenkatesan $^{3} \cdot$ Raja Selvaraj $^{1}$
}

Received: 26 March 2021 / Accepted: 2 June 2021 / Published online: 12 June 2021

(c) The Author(s) 2021

\begin{abstract}
Zinc oxide nanoflowers (ZnONFs) were prepared by employing the pod extract of Peltophorum pterocarpum as a green resource and characterized by various methods. UV-vis spectrum displayed a peak at $361 \mathrm{~nm}$ which confirmed the formation of $\mathrm{ZnO}$ nanoparticles. The optical band gap was calculated as $3.43 \mathrm{eV}$. FE-SEM images exposed the flower-like morphology and EDX portrayed strong signals for Zn and O. XRD studies substantiated signature peaks for the wurtzite phase of $\mathrm{ZnONFs}$ and the lattice parameters matched well with the literature. Mesoporous nature was confirmed by BET analysis which yielded a high specific surface area of $19.61 \mathrm{~m}^{2} / \mathrm{g}$. FTIR bands at 420.48 and $462.92 \mathrm{~cm}^{-1}$ affirmed the Zn and O bonding vibrations. The photocatalytic potential of the ZnONFs was successfully examined for the removal of methylene blue dye under natural solar light. The experimental data were fitted to Langmuir-Hinshelwood's first-order equation and the kinetic constant was calculated as $0.0114 \mathrm{~min}^{-1}$.
\end{abstract}

Keywords Zinc oxide nanoflowers · Peltophorum pterocarpum $\cdot$ Methylene Blue dye $\cdot$ Photodegradation · Green synthesis

\section{Introduction}

Nanotechnology is emerging as a forerunner in many fields in recent times. Due to the unique physicochemical properties as compared to their bulk materials, the nanomaterials are extensively explored in various domains such as food, textile, cosmetics, electronics, medical sciences, energy, construction, and environmental remediation (Varadavenkatesan et al. 2020a, b; Pandey et al. 2020a). Zinc oxide nanoparticles (ZONPs) are one such valuable metal oxide nanoparticles which have reaped attention at present due to its unique characteristics like wide bandgap, catalytic efficiency, and nontoxic nature. ZONPs are extensively used as adsorbents, photocatalysts, anti-microbial agents,

\section{Raja Selvaraj}

raja.s@manipal.edu

1 Department of Chemical Engineering, Manipal Institute of Technology, Manipal Academy of Higher Education, Manipal, Karnataka 576104, India

2 Department of Biotechnology, M.S.Ramaiah Institute of Technology, Bengaluru, Karnataka 560054, India

3 Department of Biotechnology, Manipal Institute of Technology, Manipal Academy of Higher Education, Manipal, Karnataka 576104, India drug-delivery agents, self-cleansing agents, and semiconductors (Mirzaei and Darroudi 2017).

Several conventional approaches such as chemical, physical, and electrochemical methods are used in the preparation of ZONPs. However, these popular strategies are not cost-effective and face difficulties during purification due to the formation of hazardous by-products. Moreover, the researchers also faced additional important problems such as the achievement of monodispersity and control over the morphology during the preparation of nanoparticles. To eliminate these problems, green resources such as plant extracts and microbial extracts were explored and proven as outstanding substitutes for the preparation of ZONPs (Vinayagam et al. 2020a). The synthesis processes involving these green resources are very rapid, cheap, and easily scalable. The various biomolecules present in these extracts reduce and stabilize the nanoparticles (Groiss et al. 2017). Few examples of green resources used for the preparation of ZONPs include Linum usitatissimum (Alkasir et al. 2020), Moringa oleifera (Letsholathebe et al. 2020), Salvadora persica (Alharthi et al. 2020), Ilex paraguariensis (Bandeira et al. 2020), Sambucus spp. (Alamdari et al. 2020) Abelmoschus esculentus (Mirgane et al. 2020), Peltophorum pterocarpum (Pai et al. 2019a), Cyanometra ramiflora 
(Varadavenkatesan et al. 2019) and Calliandra haematocephala (Vinayagam et al. 2020b).

Wastewaters loaded with industrial dye effluents are a major environmental concern (Pandey 2017). An example of a cationic dye in methylene blue that has far-reaching applications in diverse areas such as textile, paper and pharmaceutical sectors. It is imperative that the dye is sufficiently removed prior to the waters entering the aquatic bodies as the dye poses critical ecological and health concerns (Pandey et al. 2020b). The usual methods employed for dye elimination (e.g. adsorption) suffer from a lot of disadvantages including cost and pace of the dye transfer. Our research group has already explored the usage of the Peltophorum pterocarpum pod extract to prepare silver (Raja et al. 2015a) and iron oxide nanoparticles (Dash et al. 2019). As demonstrated in these reports, the biomolecules of the extract were responsible for the reduction and stabilization of the nanoparticles.

Therefore, in the current study, we focused on the (1) fabrication of ZONPs by utilizing the P.pterocarpum pod extract, (2) characterization, and (3) photocatalytic ability to decolorize a model pollutant-methylene blue (MB) dye in the presence of solar irradiation.

\section{Materials and methods}

\section{Materials}

Analytical grade zinc acetate dihydrate, $\mathrm{NaOH}$, and $\mathrm{MB}$ dye were purchased from Merck, India, and used without any further purification. Distilled water was used for all the experiments. Fresh pods of $P$. pterocarpum tree were collected from Manipal, India.

\section{Peltophorum pterocarpum pod extract preparation}

P. pterocarpum pod extract (PPPE) was prepared by referring to our earlier reports (Dash et al. 2019; Raja et al. 2015 b). Briefly, the pods of $P$. pterocarpum were first washed with distilled water to remove the surface dirt and then air-dried. The cleaned pods were boiled with water (1:10) to yield a light-yellow extract indicating the release of the polyphenols from the plant material. After cooling and filtering, the extract was collected and preserved in the refrigerator for future use.

\section{Production of zinc oxide nanoflowers (PP-ZnONFs)}

Nanoparticles were synthesized by mixing $50 \mathrm{~mL}$ of zinc acetate dihydrate $(50 \mathrm{mM})$ and $10 \mathrm{~mL}$ of PPPE and subsequent addition of $10 \mathrm{~mL} \mathrm{NaOH}(2 \mathrm{M})$ to form colloidal suspension on heating. Settling of suspension was observed in a course of time resulting in precipitated ZnONFs. After multiple water-washes, the particles were centrifuged and oven-dried (at $95{ }^{\circ} \mathrm{C}$ for $7 \mathrm{~h}$ ) to obtain pure PP-ZnONFs. The dried powder was pulverized using a mortar and pestle and stored in a plastic vial.

\section{Photocatalytic activity of PP-ZnONFs to degrade MB dye}

The photocatalytic potential of the PP-ZnONFs was studied by the degradation of MB dye under natural solar light. The photocatalytic experimentations were performed in a glass beaker. Initially, $40 \mathrm{mg}$ of PP-ZnONFs were mixed with $100 \mathrm{~mL}$ of MB dye (25 ppm) and stirred uniformly for $1 \mathrm{~h}$ in dark to finish adsorption-desorption process. Afterward, the contents were placed under solar irradiation on a sunny day between 10:30 AM and 3:00 PM with constant stirring. At fixed time intervals, samples were collected and the MB dye concentrations were analyzed by recording the absorption intensity $\left(\lambda_{\max }=663 \mathrm{~nm}\right)$ using $\mathrm{UV}$-vis spectroscopy.

\section{Characterization}

The synthesized PP-ZnONFs were characterized using many sophisticated methods. The synthesis of PP-ZnONFs was monitored by the absorption spectrum of colloidal suspension using a UV-visible spectrophotometer (SHIMADZUUV1700). Field Emission Scanning Electron Microscope (FE-SEM) (Carl ZEISS, Sigma, Oxford Instruments) was used to examine the individual elements and morphology of the PP-ZnONFs. Pore volume and specific surface area (SSA) were determined using the Brunauer-Emmett and Teller (BET) apparatus (Smart Instruments, Mumbai). X-ray diffraction (Rigaku Miniflex 600) spectrum was used to analyze the crystalline type. Fourier Transform Infrared Spectroscopy (FTIR-SHIMADZU-8400S) was used to investigate the specific functional moieties of the PP-ZnONFs.

\section{Results and discussions}

\section{Visual examination and UV-vis analysis}

The confirmatory spot check for the development of $\mathrm{PP}-\mathrm{ZnONFs}$ was the color change of the reaction mixture when the pale yellow PPPE (Fig. 1A) was mixed with the colorless zinc acetate solution (Fig. 1B). This leads to the formation of a colloidal suspension (Fig. 1C) upon heating. The subsequent addition of $\mathrm{NaOH}$ leads to a white precipitate (Fig. 1D) in due course. These observations were in concordance with our earlier reports for the fabrication of ZnONPs using various green resources (Varadavenkatesan et al. 2019; Vinayagam et al. 2020b; Pai et al. 2019). 


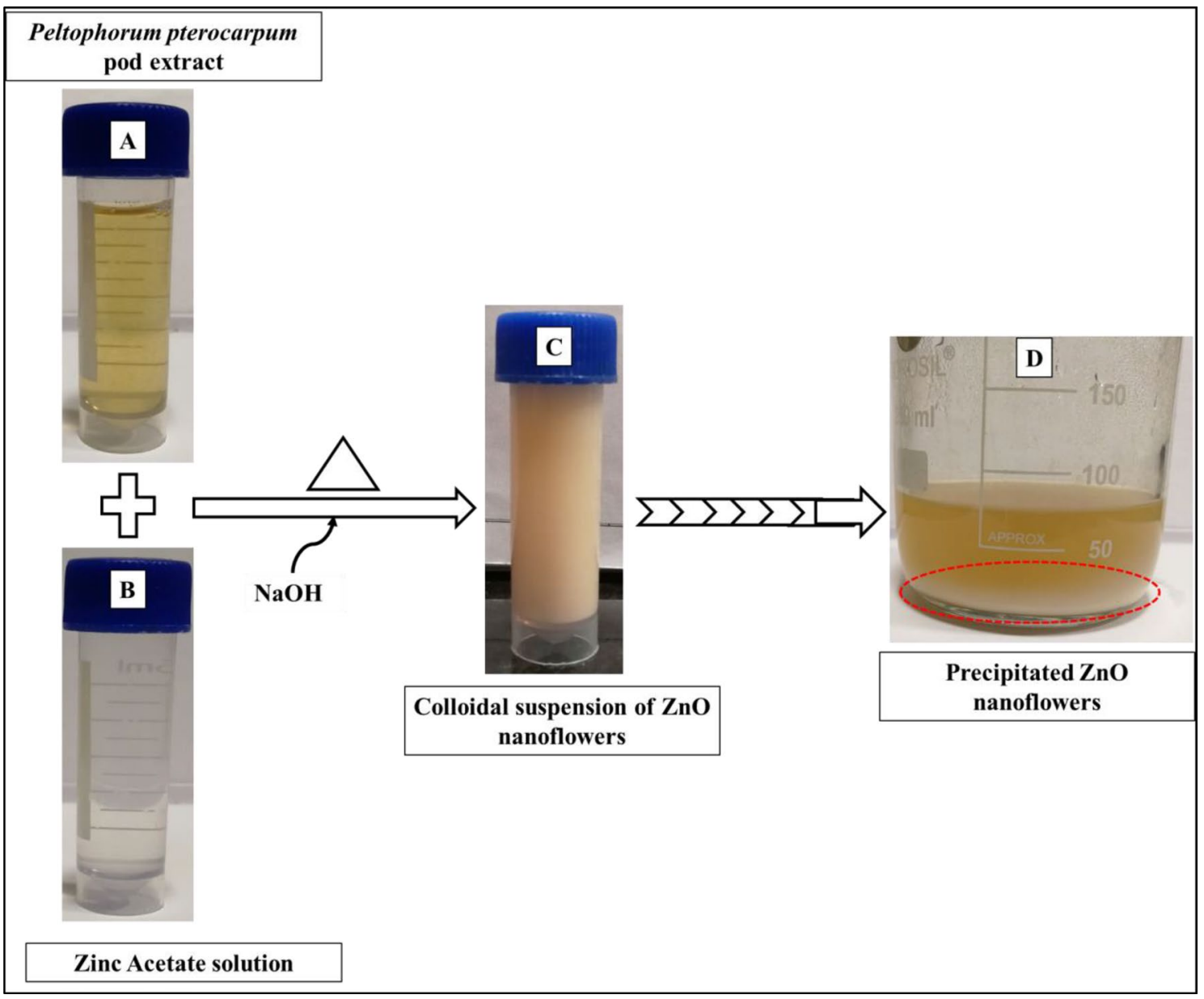

Fig. 1 Formation of PP-ZnONFs (A). P. pterocarpum pod extract. B Zinc acetate solution. C Colloidal suspension of ZnONFs. D Precipitated ZnONFs

As mentioned earlier, the PPPE contains various types of biomolecules that combine with the metallic salt, zinc acetate to form an intermediate complex through hydrogen bonding (Suresh et al. 2018). Under the basic environment, this forms metal hydroxide which yields zinc oxide nanoparticles while heating. The reduction of $\mathrm{Zn}$ was possible and spontaneous because of the fact that the standard reduction potential of biomolecules of plant materials is between 0.3 and $0.8 \mathrm{~V}$ whereas for $\mathrm{Zn}$ it is just-0.76 V (Haynes 2014). Apart from the reduction, the biomolecules help in the stabilization of nanoparticles by self-assembling and lead to the formation of flower-like nanostructures. A similar mechanism was described for the ZnONFs synthesized using Bacillus licheniformis extract and zinc acetate precursor (Tripathi et al. 2014).

Following the visual observation, the PP-ZnONFs development was confirmed by making a PP-ZnONFs dispersion in water and conducting UV-vis spectral examination of the same. As evinced from Fig. 2, a distinctive absorption peak was observed at $361 \mathrm{~nm}$ due to the surface plasmon resonance (SPR) of zinc oxide nanoparticles (Varadavenkatesan et al. 2019). The absence of other peaks substantiated the purity of the ZnONFs. The surface plasmon resonance (SPR) of the ZnONPs alters the particle morphology and dielectric constant of the response channel (Chakraborty et al. 2020). The optical bandgap of PP-ZnONFs was calculated using the Planck-Einstein relationship and found out as $3.43 \mathrm{eV}$. The value obtained was concordant with the previously reported literature. For example, bandgap values of $3.4 \mathrm{eV}$ and $3.44 \mathrm{eV}$ were obtained in studies using Jatropha gossypifolia leaf extract and Cyanometra ramiflora leaf extracts (Varadavenkatesan et al. 2019; Krishnan et al. 2020).

\section{SEM and EDX studies}

The FESEM image of PP-ZnONFs with the magnification of $20 \mathrm{kX}$ and $80 \mathrm{kX}$ are shown in Fig. 3A and B. Aggregated flower-shaped $\mathrm{ZnO}-\mathrm{NFs}$ were observed. Clusters of particles were observed due to crystal growth. The 


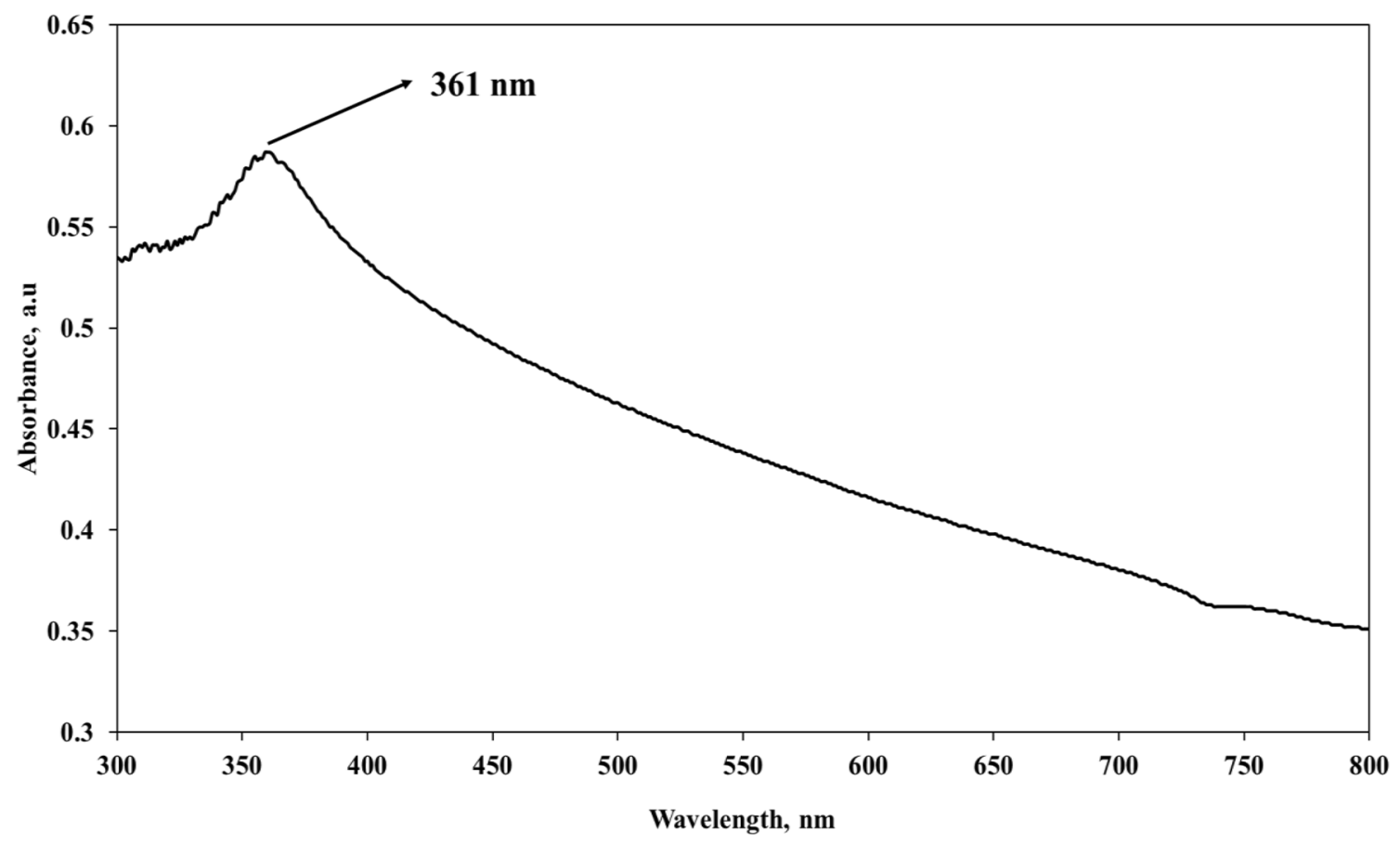

Fig. 2 UV-visible spectroscopic analysis of PP-ZnONFs

formation of aggregations was possibly owing to the divergence, electrostatic attraction, and high surface energy PPZnONFs (Darvishi et al. 2019). The presence of organic compounds in the extract may also cause agglomeration (Vinayagam et al. 2020b). The average thickness of the nanoflower petals was calculated as $59 \mathrm{~nm}$ using ImageJ software. The observation of the nanoflower-shaped zinc oxide nanoparticles is common for the green synthesis using the extracts of P. pterocarpum (Pai et al. 2019), E. sanguinea (Ekennia et al. 2020) and W. coagulans (Hasan et al. 2021).

The EDX spectra (Fig. 3C) showed the presence of zinc, oxygen, and carbon atoms. To be specific, $\mathrm{Zn}$ indicated strong signals at $8.6 \mathrm{keV}$ and $1 \mathrm{keV}$. Similarly, $\mathrm{O}$ exhibited a strong signal at $0.5 \mathrm{keV}$. Therefore, the existence of these signals corroborated the establishment of $\mathrm{ZnO}$ nanoparticles. The $\mathrm{C}$ signal might be because of the participation of phytochemicals during the synthesis and capping of ZnONFs (Pai et al. 2019).

The higher weight percentage of $\mathrm{Zn}(66.59 \%)$ and $\mathrm{O}$ $(24.29 \%)$ witnessed the presence of $\mathrm{ZnO}$ nanoparticles. Also, the atomic compositions (\%) of the individual elements in the sample were observed as, $\mathrm{Zn}$ : 30.91, O: 46.06, and C: 23.03. Similar kinds of atomic compositions (\%), Zn: 36, O: 44.85 and C: 15.68 were reported for the synthesis of ZnONPs by utilizing Justicia spicigera leaf extract (Soto-Robles et al. 2021). The purity of the $\mathrm{ZnO}$ nanoparticles was ascertained by the non-appearance of other peaks.

\section{XRD studies}

The XRD image of the sample with the Miller indices of peaks is depicted in Fig. 4. The diffraction signals at the $2 \theta$ values of $31.31^{\circ}, 34.06^{\circ}, 35.84^{\circ}, 47.20^{\circ}, 56.23^{\circ}, 62.48^{\circ}$, $67.62^{\circ}, 68.74^{\circ}$ and $76.74^{\circ}$ corresponded to $\left(\begin{array}{lll}1 & 0 & 0\end{array}\right),\left(\begin{array}{lll}0 & 0 & 2\end{array}\right)$, (1 $\left.\begin{array}{lll}0 & 1\end{array}\right),\left(\begin{array}{lll}1 & 0 & 2\end{array}\right),\left(\begin{array}{lll}1 & 1 & 0\end{array}\right),\left(\begin{array}{lll}1 & 0 & 3\end{array}\right),\left(\begin{array}{lll}1 & 1 & 2\end{array}\right),\left(\begin{array}{lll}2 & 0 & 1\end{array}\right)$ and $\left(\begin{array}{lll}2 & 0 & 2\end{array}\right)$ Miller indices which were precisely indexed to the pure hexagonal wurtzite phase of zinc oxide nanoparticles (JCPDS Card No.: 36-1451) (Ekennia et al. 2020). The lattice parameters ' $a$ ' and 'c' were computed as $3.269 \AA$ and $5.2092 \AA$, respectively, which matched with the literature (Pudukudy and Yaakob 2015). The ratio of the lattice parameters "c/a" was equal to 1.594 which matched well with the ZnONPs synthesized using the flower extract of Aspalathus linearis (Diallo et al. 2015).

The sharp and distinct diffraction signals indicated the high crystalline nature of the nanoparticles. No other signals were observed. The full width at half maximum (FWHM), ' $\beta$ ' of these peaks yielded a mean crystallite size of $17.79 \mathrm{~nm}$ (Table 1) calculated by the Debye-Scherrer equation which matched well with previous studies (Alamdari et al. 2020; Vinayagam et al. 2020b).

\section{BET studies}

It is well-known that the flower-like ZnONPs have more SSA as compared to other morphological forms (Luo et al. 2014). The SSA and pore volume were analyzed by BET 


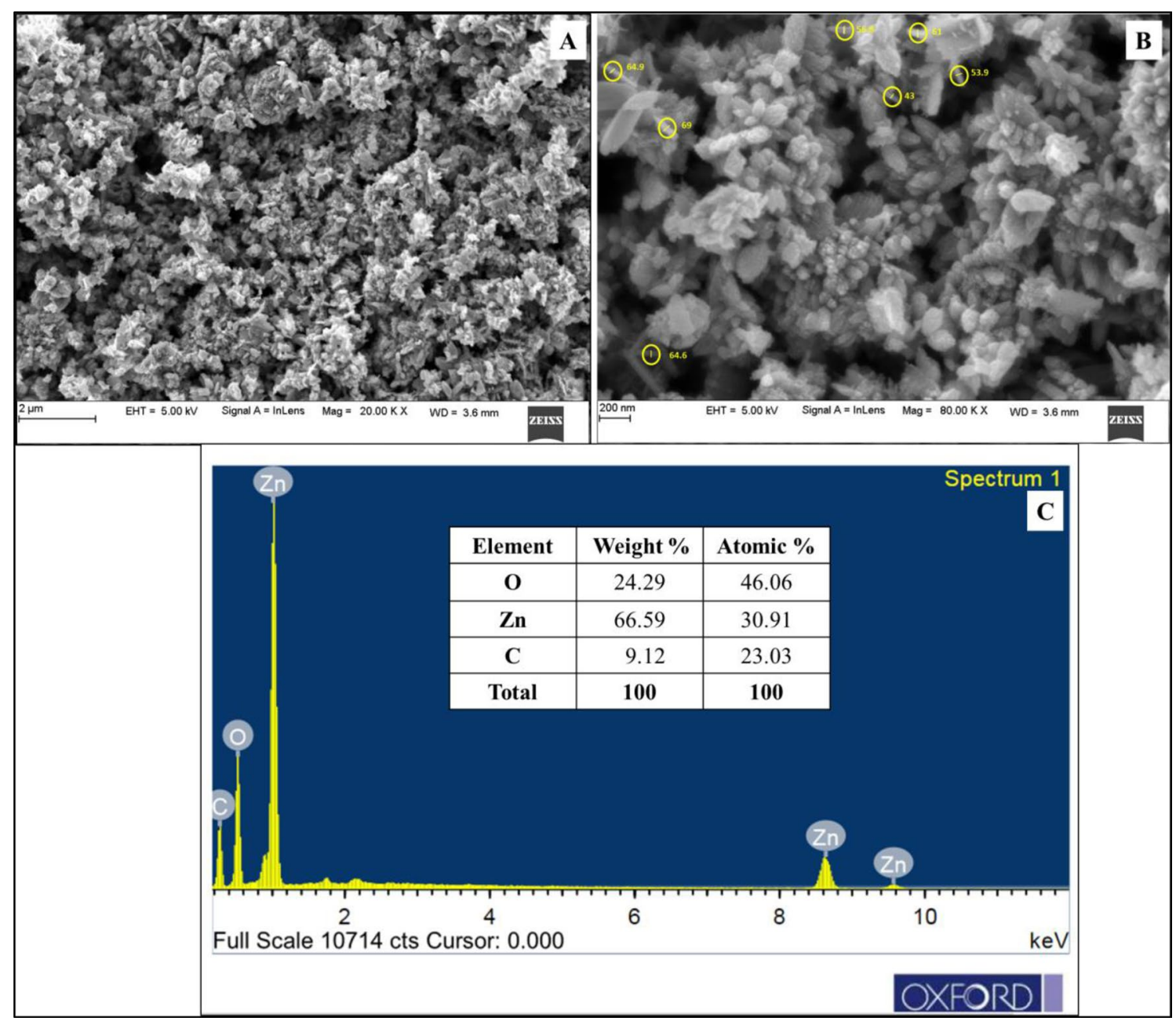

Fig. 3 A FESEM image of PP-ZnONFs at $20 \mathrm{kX}$ magnification. B FESEM image of PP-ZnONFs at $80 \mathrm{kX}$ magnification and $\mathbf{C}$ EDX spectrum of PP-ZnONFs

method. As expected, the PP-ZnONFs showed a high SSA of $19.61 \mathrm{~m}^{2} / \mathrm{g}$ which was almost 6 times higher than that of commercial $\mathrm{ZnO}$ nanoparticles $\left(3.23 \mathrm{~m}^{2} / \mathrm{g}\right)$ (Chakrabarti and Dutta 2004). It is apparent from Table 2 that the SSA obtained in the present work is much higher than the other green synthesized $\mathrm{ZnO}$ nanoparticles. Besides, the pore volume was $0.0826 \mathrm{~cm}^{3} / \mathrm{g}$ which confirmed the mesoporous structure $(16.85 \mathrm{~nm})$ of pores. Therefore, the high surface area and mesoporous structure of PP-ZnONFs make them vital representatives for many applications.

\section{FTIR studies}

The composition of the PP-ZnONFs, with respect to the functional moieties, was deduced from the FTIR spectrum (Fig. 5). The broadband in the range of $3400-3600 \mathrm{~cm}^{-1}$ was mainly due to the stretching vibration of the phenolic hydroxyl group (Darvishi et al. 2019; Soto-Robles et al. 2021; Lu et al. 2019). The band at $2359 \mathrm{~cm}^{-1}$ was due to the $\mathrm{C}-\mathrm{H}$ stretching vibrations of aromatic aldehyde (Akbarian et al. 2020). A weak band at $1541 \mathrm{~cm}^{-1}$ corresponded to $\mathrm{C}=\mathrm{C}$ stretching bonds of aromatic compounds in the extract (Vinayagam et al. 2020b; Hu et al. 2019). The band at $1175 \mathrm{~cm}^{-1}$ belonged to C-O stretching (Darvishi et al. 2019; Chen et al. 2019).

The bands at 637,718 , and $781 \mathrm{~cm}^{-1}$ in the fingerprint region corresponded to aromatic $\mathrm{C}-\mathrm{H}$ groups in the extract (Darvishi et al. 2019). The bands at 421 and $463 \mathrm{~cm}^{-1}$ may be attributed to characteristic $\mathrm{Zn}$ and $\mathrm{O}$ bonding vibrations (Suresh et al. 2018; Li et al. 2019; Gopalakrishnan et al. 2019). Therefore, the signals for various functional moieties ascertained the contribution of the phytochemicals present in the PPPE for the formation of $\mathrm{ZnONFs.}$

\section{Photocatalytic activity of PP-ZnONFs to degrade MB dye}

The UV-vis spectral images of photodegradation of MB dye by PP-ZnONFs were shown in Fig. 6A along with the

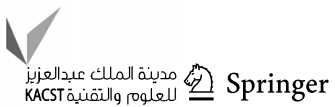


Fig. 4 XRD spectrum of PPZnONFs

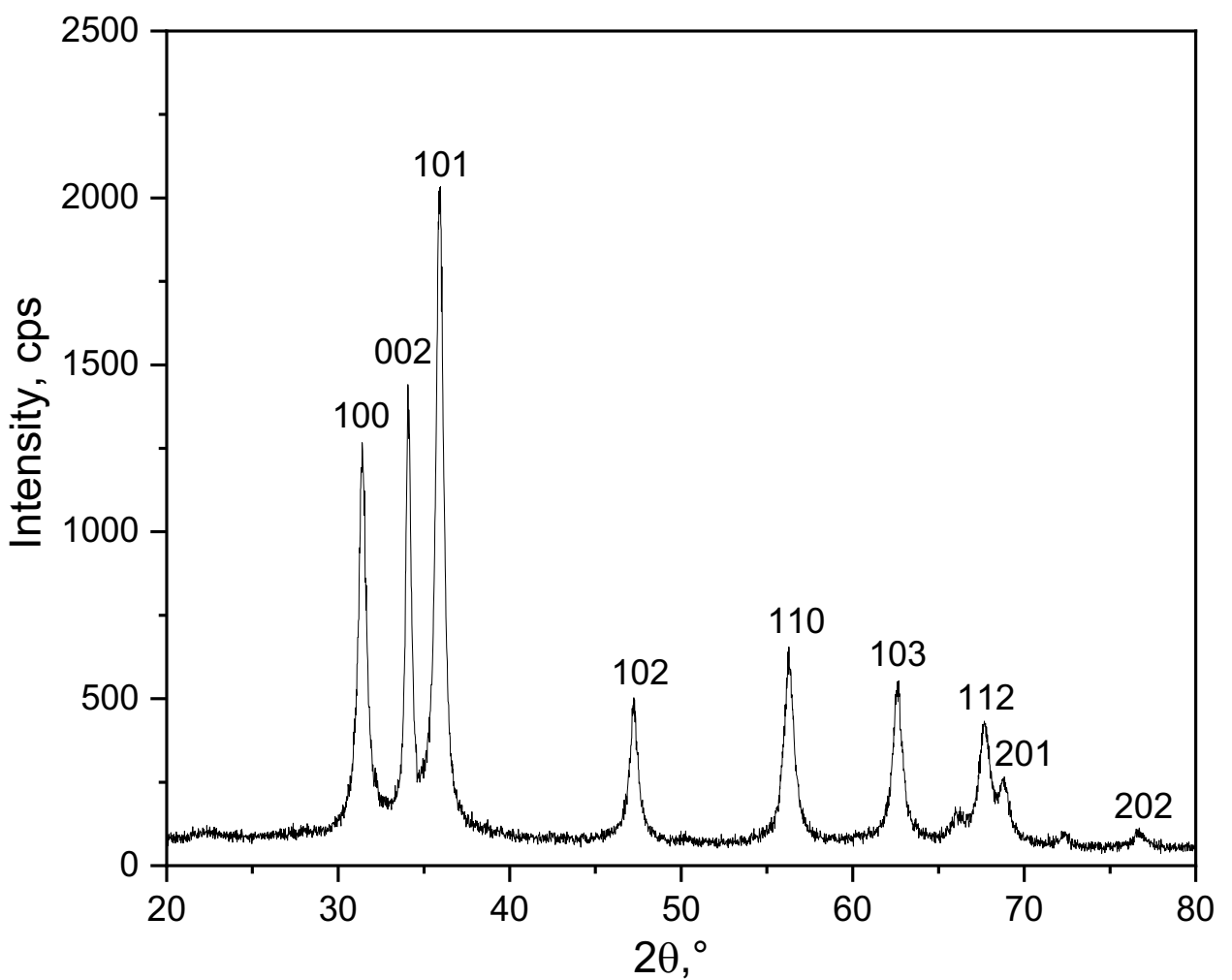

Table 1 Computation of average crystallite size of PP-ZnONFs

\begin{tabular}{|c|c|c|c|c|}
\hline S.no & $\begin{array}{l}2 \theta \\
\left({ }^{\circ}\right)\end{array}$ & "h k l" plane & $\begin{array}{l}\beta \\
\left({ }^{\circ}\right)\end{array}$ & $\begin{array}{l}\text { Crystallite size } \\
(\mathrm{nm})\end{array}$ \\
\hline 1 & 31.31 & 100 & 0.4742 & 19.33 \\
\hline 2 & 34.06 & 002 & 0.3691 & 25.01 \\
\hline 3 & 35.84 & 101 & 0.5169 & 17.95 \\
\hline 4 & 47.20 & 102 & 0.5246 & 18.36 \\
\hline 5 & 56.23 & 110 & 0.7004 & 14.288 \\
\hline 6 & 62.48 & 103 & 0.6108 & 16.90 \\
\hline 7 & 67.62 & 112 & 0.6374 & 16.67 \\
\hline 8 & 68.74 & 201 & 0.7737 & 13.82 \\
\hline \multirow[t]{2}{*}{9} & 76.74 & 202 & 0.6329 & 17.79 \\
\hline & & & & Average $=17.79$ \\
\hline
\end{tabular}

discoloration of MB dye as a function of time. It can be witnessed from the images that the MB dye solution became colorless after $180 \mathrm{~min}$ of solar irradiation. The decrement in the absorbance of $\mathrm{MB}$ dye at $\lambda_{\max }=663 \mathrm{~nm}$ substantiated the degradation process. From Fig. 6B, it can be inferred that $88.39 \%$ of the MB dye was photodegraded in $180 \mathrm{~min}$ solar irradiation.

It can be inferred from Table 3 that the degradation efficiency of MB dye by the PP-ZnONFs is much higher than the recent reports on the green synthesized $\mathrm{ZnO}$ nanoparticles. This enhanced photocatalytic activity of the PPZnONFs may be due to the small particle size, mesoporosity, and high specific surface area.

The kinetic data of the photodegradation was fitted to the Langmuir-Hinshelwood first-order equation as given by,
Table 2 BET surface area of various green synthesised $\mathrm{ZnO}$ nanoparticles

\begin{tabular}{lcl}
\hline Source & SSA $\left(\mathrm{m}^{2} / \mathrm{g}\right)$ & Ref \\
\hline Calliandra haematocephala leaf & 9.18 & Vinayagam et al. (2020b) \\
Musa balbisiana peel & 11.402 & Tamuly et al. (2015) \\
Peltophorum pterocarpum leaf & 13.56 & Pai et al. (2019) \\
Cyanometra ramiflora leaf & 16.27 & Varadavenkatesan et al. (2019) \\
Peltophorum pterocarpum pod & 19.61 & This study \\
\hline
\end{tabular}


Fig. 5 FTIR spectrum of PPZnONFs

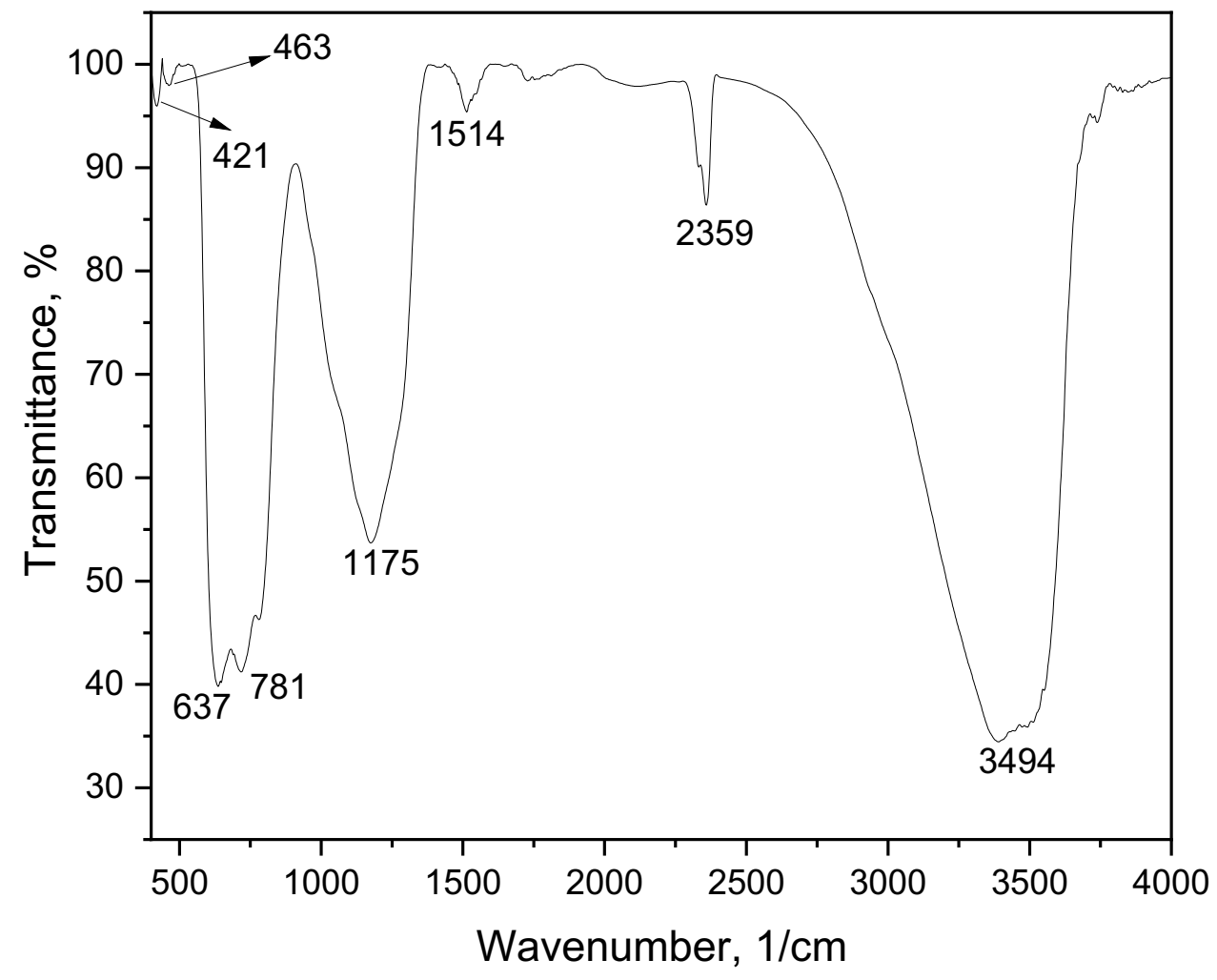

$\ln \left[\frac{A_{\mathrm{f}}}{A_{0}}\right]=-k_{\mathrm{phd}} t$

where " $t$ " is the solar irradiation time in min, $A_{0}$ and $A_{\mathrm{f}}$ are the initial and final concentration of MB dye and $k_{\text {phd }}$ is the degradation constant. Figure 6C shows the relationship between $\ln \left[\frac{A_{\mathrm{f}}}{A_{0}}\right]$ and $t$ with linear relationship and the value of $k_{\text {phd }}$ was determined as $0.0114 \mathrm{~min}^{-1}$.

The incident sunlight has more energy than the bandgap energy of PP-ZnONFs. Therefore, as depicted in Fig. 7 the photocatalytic mechanism involves the creation of electrons $\left(e^{-}\right)$in the conduction band (CB) and holes $\left(h^{+}\right)$in the valance band (VB) when sunlight irradiates on the surface of PP-ZnONFs. These generated $e^{-}$converts dissolved $\mathrm{O}_{2}$ to form superoxide free radicals $\left(\mathrm{O}_{2}^{-}\right)$and $h^{+}$produce $\cdot \mathrm{OH}$ free radicals. These intermediates are highly active which act as oxidizing and reducing agents and thus are responsible for the photodegradation of MB dye as explained by many researchers (Tabrizi Hafez Moghaddas et al. 2019; Ganesh et al. 2019; Pandimurugan and Thambidurai 2016).

\section{Conclusion}

Green synthesized Zinc oxide nanoflowers (ZnONFs) have been synthesized by utilizing the pod extract of Peltophorum pterocarpum for the first time. The formation of $\mathrm{ZnO}$ nanoparticles was confirmed by the characteristic signals shown in UV-vis spectrum, EDX image, XRD pattern, and FTIR spectrum. FESEM image confirmed the flower-like nanostructures with few aggregations and BET analysis ascertained the mesoporosity with a relatively higher specific surface area than commercial $\mathrm{ZnO}$ nanoparticles. $88.39 \%$ of $\mathrm{MB}$ dye was photodegraded under sunlight within $180 \mathrm{~min}$ in the presence of ZnONFs. Therefore, the green-synthesized $\mathrm{ZnONFs}$ obtained in the present study can play a significant role in the removal of harmful dyes present in industrial wastewater. 


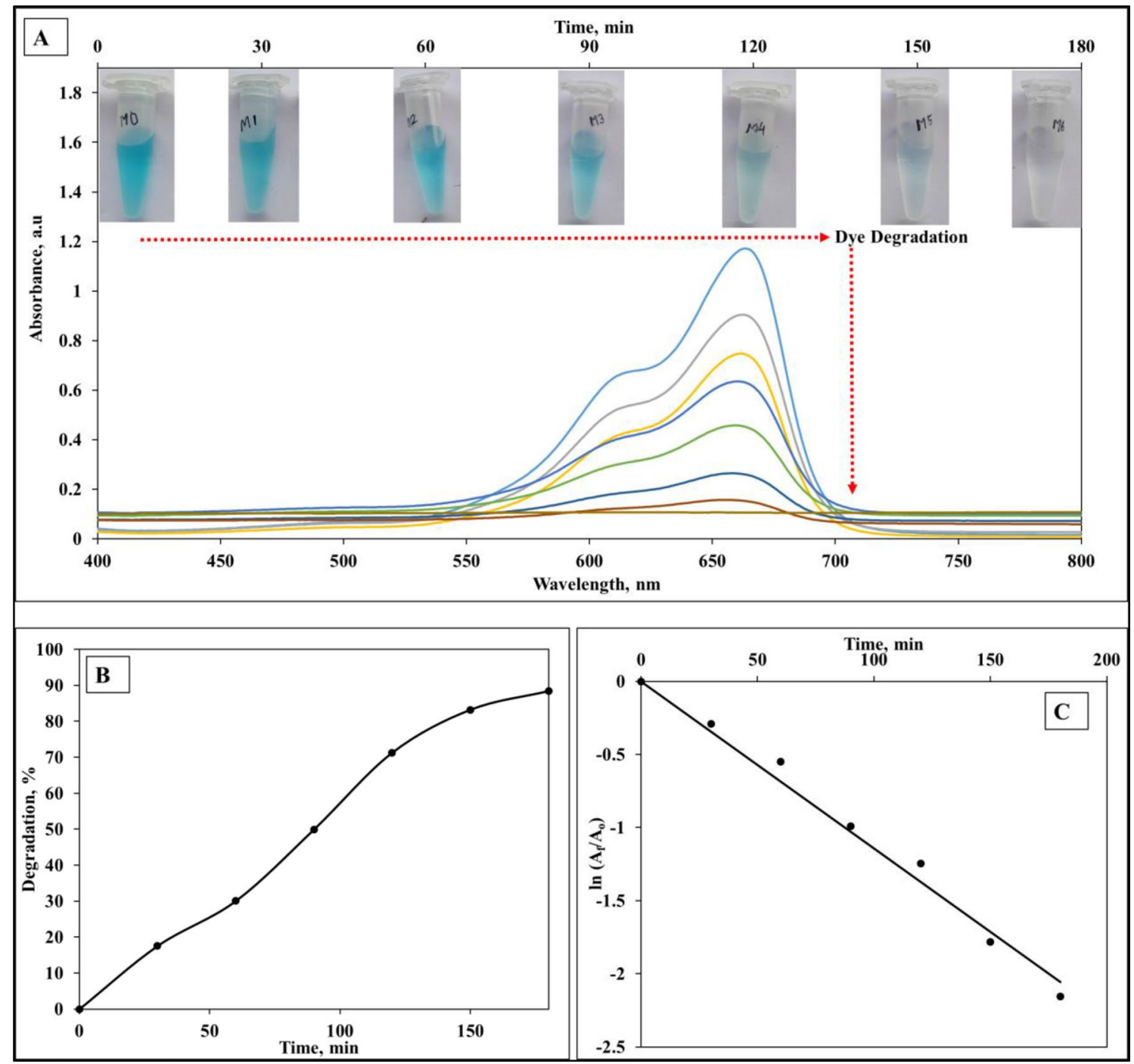

Fig. 6 Photocatalytic degradation of MB dye by PP-ZnONFs. A UV-vis spectra and color change of MB dye under different time intervals. B Plot of $\%$ degradation of MB dye vs time. C Plot of $\ln \left(A_{\mathrm{f}} / A_{0}\right)$ vs time

Table 3 Recent reports on the photocatalytic potential of various green synthesised $\mathrm{ZnO}$ nanoparticles to degrade $\mathrm{MB}$ dye

\begin{tabular}{llllll}
\hline S.no & Green resource & Irradiation source & $\begin{array}{l}\text { Time of } \\
\text { degrada- } \\
\text { tion } \\
(\mathrm{min})\end{array}$ & Degradation (\%) & Ref \\
\hline 1 & Cassia fistula & Sunlight & 120 & 50 & Suresh et al. (2015) \\
2 & Suaeda japonica Makino & UV light & 60 & 54 & Shim et al. (2019) \\
3 & Linnum usitatissimum & UV light & 120 & 80 & Tabrizi Hafez \\
& & & & & Moghaddas et al. \\
4 & Bacillus licheniformis & UV light & 60 & 83 & Tripathi et al. (2014) \\
5 & Camellia sinensis & UV light & 120 & 84 & Nava et al. (2017) \\
6 & P. pterocarpum pods & Sunlight & 180 & $88.39 \%$ & This study \\
\hline
\end{tabular}




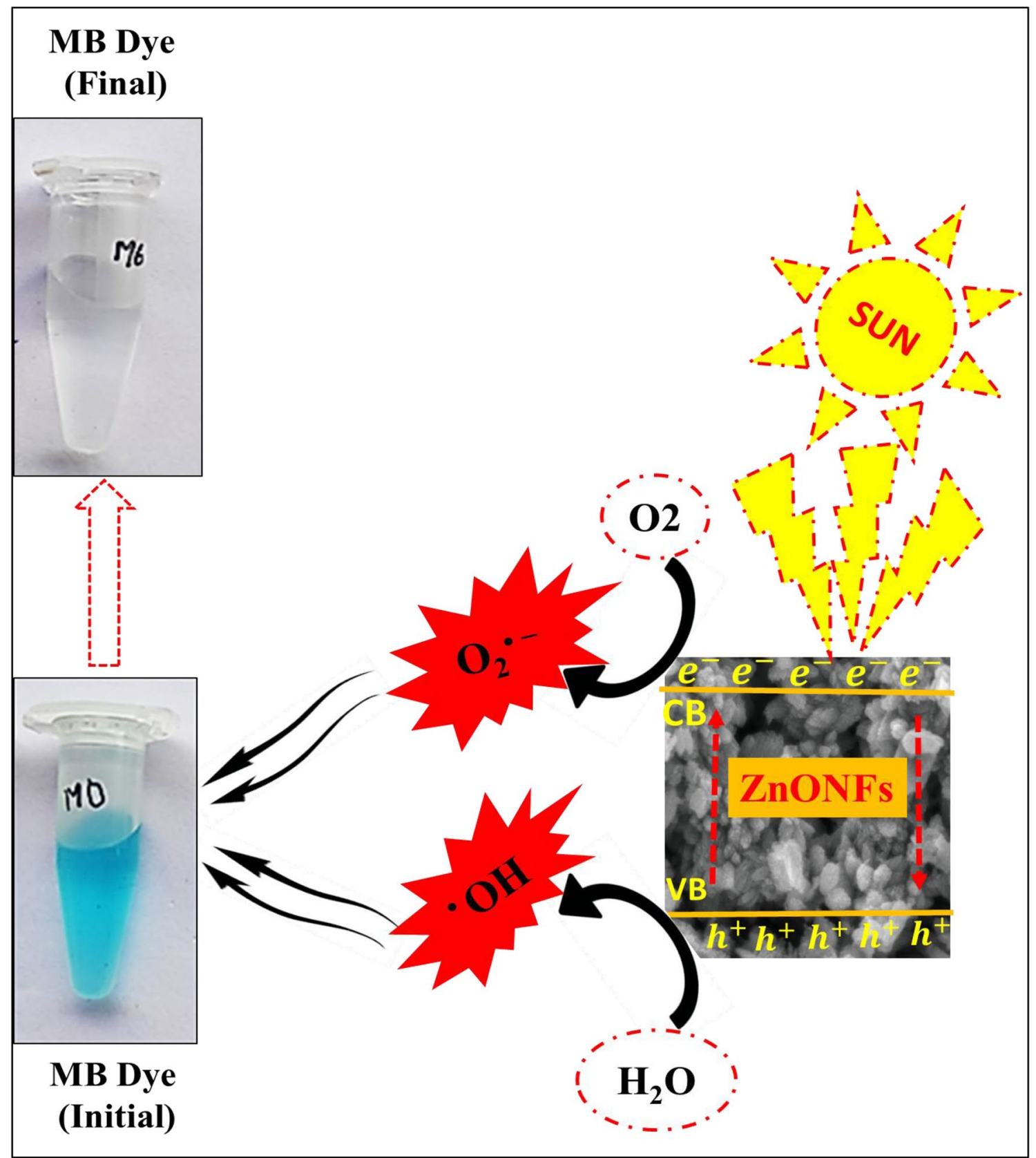

Fig. 7 Mechanism of photocatalytic degradation of MB dye by PP-ZnONFs

Acknowledgements The authors are grateful to the Department of Chemical Engineering, Manipal Institute of Technology, Manipal Academy of Higher Education for providing lab facilities and equipment to perform this study. The authors thank DST PURSE Laboratory, Mangalore University, Mangalagangotri for providing the FE-SEM and EDS facilities.

Funding Open access funding provided by Manipal Academy of Higher Education, Manipal.

Data availability The raw/processed data required to reproduce these findings cannot be shared at this time as the data also forms part of an ongoing study.

\section{Declarations}

Conflict of interest The authors declare that they have no conflict of interest.

Open Access This article is licensed under a Creative Commons Attribution 4.0 International License, which permits use, sharing, adaptation, distribution and reproduction in any medium or format, as long as you give appropriate credit to the original author(s) and the source, provide a link to the Creative Commons licence, and indicate if changes were made. The images or other third party material in this article are included in the article's Creative Commons licence, unless indicated otherwise in a credit line to the material. If material is not included in 
the article's Creative Commons licence and your intended use is not permitted by statutory regulation or exceeds the permitted use, you will need to obtain permission directly from the copyright holder. To view a copy of this licence, visit http://creativecommons.org/licenses/by/4.0/.

\section{References}

Akbarian M, Mahjoub S, Mohammad S, Zabihi E (2020) Biointerfaces Green synthesis, formulation and biological evaluation of a novel $\mathrm{ZnO}$ nanocarrier loaded with paclitaxel as drug delivery system on MCF-7 cell line. Colloids Surf B Biointerfaces 186:110686. https://doi.org/10.1016/j.colsurfb.2019.110686

Alamdari S, Ghamsari MS, Lee C, Han W, Park HH, Tafreshi MJ, Afarideh H, Ara MHM (2020) Preparation and characterization of zinc oxide nanoparticles using leaf extract of sambucus ebulus. Appl Sci 10:1-19. https://doi.org/10.3390/app10103620

Alharthi FA, Alghamdi AA, Alothman AA, Almarhoon ZM, Alsulaiman MF, Al-Zaqri N (2020) Green synthesis of zno nanostructures using salvadora persica leaf extract: applications for photocatalytic degradation of methylene blue dye. Curr Comput-Aided Drug Des. https://doi.org/10.3390/cryst10060441

Alkasir M, Samadi N, Sabouri Z, Mardani Z, Khatami M, Darroudi M (2020) Evaluation cytotoxicity effects of biosynthesized zinc oxide nanoparticles using aqueous Linum Usitatissimum extract and investigation of their photocatalytic activityackn. Inorg Chem Commun 119:108066. https://doi.org/10.1016/j.inoche.2020. 108066

Bandeira M, Possan AL, Pavin SS, Raota CS, Vebber MC, Giovanela M, Roesch-Ely M, Devine DM, Crespo JS (2020) Mechanism of formation, characterization and cytotoxicity of green synthesized zinc oxide nanoparticles obtained from Ilex paraguariensis leaves extract. Nano-Struct Nano-Obj 24:100532. https://doi.org/ 10.1016/j.nanoso.2020.100532

Chakrabarti S, Dutta BK (2004) Photocatalytic degradation of model textile dyes in wastewater using $\mathrm{ZnO}$ as semiconductor catalyst. J Hazard Mater 112:269-278

Chakraborty S, Farida JJ, Simon R, Kasthuri S, Mary NL (2020) Averrhoe carrambola fruit extract assisted green synthesis of zno nanoparticles for the photodegradation of congo red dye. Surf Interfaces 19:100488. https://doi.org/10.1016/j.surfin. 2020.100488

Chen L, Batjikh I, Hurh J, Han Y, Huo Y, Ali H, Li JF, Rupa EJ, Ahn JC, Mathiyalagan R, Yang DC (2019) Green synthesis of zinc oxide nanoparticles from root extract of Scutellaria baicalensis and its photocatalytic degradation activity using methylene blue. Optik (stuttg) 184:324-329. https://doi.org/10.1016/j.ijleo. 2019.03.051

Darvishi E, Kahrizi D, Arkan E (2019) Comparison of different properties of zinc oxide nanoparticles synthesized by the green (using Juglans regia L. leaf extract) and chemical methods. J Mol Liq 286:110831. https://doi.org/10.1016/j.molliq.2019.04. 108

Dash A, Ahmed MT, Selvaraj R (2019) Mesoporous magnetite nanoparticles synthesis using the Peltophorum pterocarpum pod extract, their antibacterial efficacy against pathogens and ability to remove a pollutant dye. J Mol Struct 1178:268-273

Diallo A, Ngom BD, Park E, Maaza M (2015) Green synthesis of ZnO nanoparticles by Aspalathus linearis: structural \& optical properties. J Alloys Compd 646:425-430. https://doi.org/10.1016/j.jallc om.2015.05.242

Ekennia AC, Uduagwu DN, Nwaji NN, Oje OO, Emma-Uba CO, Mgbii SI, Olowo OJ, Nwanji OL (2020) Green synthesis of biogenic zinc oxide nanoflower as dual agent for photodegradation of an organic dye and tyrosinase inhibitor. J Inorg Organomet Polym Mater. https://doi.org/10.1007/s10904-020-01729-w

Ganesh M, Lee SG, Jayaprakash J, Mohankumar M, Jang HT (2019) Hydnocarpus alpina Wt extract mediated green synthesis of $\mathrm{ZnO}$ nanoparticle and screening of its anti-microbial, free radical scavenging, and photocatalytic activity. Biocatal Agric Biotechnol 19:101129. https://doi.org/10.1016/j.bcab.2019.101129

Gopalakrishnan Y, Tun U, Onn H, Al-gheethi A, Tun U, Onn H, Maya R, Radin S, Tun U, Onn H, Tun U, Onn H (2019) Green synthesis of $\mathrm{ZnO}$ nanoparticles by Coriandrum sativum leaf extract : structural and optical properties green synthesis of $\mathrm{ZnO}$ nanoparticles by Coriandrum sativum leaf extract : structural and optical properties AQ1. Desalin Water Treat. https://doi.org/10.5004/dwt. 2019.24584

Groiss S, Selvaraj R, Varadavenkatesan T, Vinayagam R (2017) Structural characterization, antibacterial and catalytic effect of iron oxide nanoparticles synthesised using the leaf extract of $C y n-$ ometra ramiflora. J Mol Struct 1128:572-578. https://doi.org/10. 1016/j.molstruc.2016.09.031

Hasan M, Altaf M, Zafar A, Hassan SG, Ali Z, Mustafa G, Munawar T, Saif MS, Tariq T, Iqbal F, Khan MW, Mahmood A, Mahmood N, Shu X (2021) Bioinspired synthesis of zinc oxide nano-flowers: a surface enhanced antibacterial and harvesting efficiency. Mater Sci Eng C 119:111280. https://doi.org/10.1016/j.msec.2020. 111280

Haynes WM (2014) CRC handbook of chemistry and physics. CRC Press

Hu D, Si W, Qin W, Jiao J, Li X, Gu X, Hao Y (2019) Cucurbita pepo leaf extract induced synthesis of zinc oxide nanoparticles, characterization for the treatment of femoral fracture. J Photochem Photobiol B Biol 195:12-16. https://doi.org/10.1016/j.jphotobiol. 2019.04.001

Krishnan BR, Selvakumar MRM, Sasikumar SKA, Geerthi DV (2020) A facile green approach of cone-like ZnO NSs synthesized via jatropha gossypifolia leaves extract for photocatalytic and biological activity. J Inorg Organomet Polym Mater. https://doi.org/10. 1007/s10904-020-01576-9

Letsholathebe D, Thema FT, Mphale K, Maabong K, Maria Magdalane C (2020) Green synthesis of $\mathrm{ZnO}$ doped Moringa oleifera leaf extract using Titon yellow dye for photocatalytic applications. Today Proc Mater. https://doi.org/10.1016/j.matpr.2020.05.119

Li JF, Rupa EJ, Hurh J, Huo Y, Chen L, Han Y, Chan Ahn J, Park JK, Lee HA, Mathiyalagan R, Yang D-C (2019) Cordyceps militaris fungus mediated zinc oxide nanoparticles for the photocatalytic degradation of methylene blue dye. Optik (stuttg) 183:691-697. https://doi.org/10.1016/j.ijleo.2019.02.081

Lu J, Batjikh I, Hurh J, Han Y, Ali H (2019) Photocatalytic degradation of methylene blue using biosynthesized zinc oxide nanoparticles from bark extract of Kalopanax septemlobus. Opt-Int J Light Electron Opt 182:980-985. https://doi.org/10.1016/j.ijleo.2018.12.016

Luo J, Ma SY, Sun AM, Cheng L, Yang GJ, Wang T, Li WQ, Li XB, Mao YZ, GZ DJ (2014) Ethanol sensing enhancement by optimizing $\mathrm{ZnO}$ nanostructure: From 1D nanorods to 3D nanoflower. Mater Lett 137:17-20. https://doi.org/10.1016/j.matlet.2014.08. 108

Mirgane N, Shivankar V, Kotwal S, Wadhawa G, Sonawale M (2020) Degradation of dyes using biologically synthesized zinc oxide nanoparticles. Mater Today Proc. https://doi.org/10.1016/j.matpr. 2020.06.037

Mirzaei H, Darroudi M (2017) Zinc oxide nanoparticles: biological synthesis and biomedical applications. Ceram Int 43:907-914

Nava OJ, Luque PA, Gómez-Gutiérrez CM, Vilchis-Nestor AR, Castro-Beltrán A, Mota-González ML, Olivas A (2017) Influence of Camellia sinensis extract on zinc oxide nanoparticle green 
synthesis. J Mol Struct 1134:121-125. https://doi.org/10.1016/j. molstruc.2016.12.069

Pai S, H S, Varadavenkatesan T, Vinayagam R, Selvaraj R (2019a) Photocatalytic zinc oxide nanoparticles synthesis using Peltophorum pterocarpum leaf extract and their characterization. Optik (stuttg) 185:248-255. https://doi.org/10.1016/j.ijleo.2019.03.101

Pandey S (2017) A comprehensive review on recent developments in bentonite-based materials used as adsorbents for wastewater treatment. J Mol Liq 241:1091-1113. https://doi.org/10.1016/j. molliq.2017.06.115

Pandey S, Do JY, Kim J, Kang M (2020a) Fast and highly efficient catalytic degradation of dyes using $\kappa$-carrageenan stabilized silver nanoparticles nanocatalyst. Carbohydr Polym 230:115597. https:// doi.org/10.1016/j.carbpol.2019.115597

Pandey S, Do JY, Kim J, Kang M (2020b) Fast and highly efficient removal of dye from aqueous solution using natural locust bean gum based hydrogels as adsorbent. Int J Biol Macromol 143:6075. https://doi.org/10.1016/j.ijbiomac.2019.12.002

Pandimurugan R, Thambidurai S (2016) Novel seaweed capped $\mathrm{ZnO}$ nanoparticles for effective dye photodegradation and antibacterial activity. Adv Powder Technol 27:1062-1072

Pudukudy M, Yaakob Z (2015) Facile synthesis of quasi spherical ZnO nanoparticles with excellent photocatalytic activity. J Clust Sci. https://doi.org/10.1007/s10876-014-0806-1

Raja S, Ramesh V, Thivaharan V (2015a) Antibacterial and anticoagulant activity of silver nanoparticles synthesised from a novel source-pods of Peltophorum pterocarpum. J Ind Eng Chem 29:257-264. https://doi.org/10.1016/j.jiec.2015.03.033

Raja S, Ramesh V, Thivaharan V (2015b) Antibacterial and anticoagulant activity of silver nanoparticles synthesised from a novel source-pods of Peltophorum pterocarpum. J Ind Eng Chem 29:257-264. https://doi.org/10.1016/j.jiec.2015.03.033

Tabrizi Hafez Moghaddas SM, Elahi B, Darroudi M, Javanbakht V (2019) Green synthesis of hexagonal-shaped zinc oxide nanosheets using mucilage from flaxseed for removal of methylene blue from aqueous solution. J Mol Liq 296:111834. https:// doi.org/10.1016/j.molliq.2019.111834

Shim YJ, Soshnikova V, Anandapadmanaban G, Mathiyalagan R, Jimenez Perez ZE, Markus J, Ju Kim Y, Castro-Aceituno V, Yang DC (2019) Zinc oxide nanoparticles synthesized by Suaeda japonica Makino and their photocatalytic degradation of methylene blue. Optik (stuttg). 182:1015-1020. https://doi.org/10.1016/j.ijleo. 2018.11.144

Soto-Robles CA, Nava O, Cornejo L, Lugo-Medina E, Vilchis-Nestor AR, Castro-Beltrán A, Luque PA (2021) Biosynthesis, characterization and photocatalytic activity of $\mathrm{ZnO}$ nanoparticles using extracts of Justicia spicigera for the degradation of methylene blue. J Mol StrUct. https://doi.org/10.1016/j.molstruc.2020. 129101

Suresh D, Nethravathi PC, Rajanaika H, Nagabhushana H, Sharma SC (2015) others, Green synthesis of multifunctional zinc oxide $(\mathrm{ZnO})$ nanoparticles using Cassia fistula plant extract and their photodegradative, antioxidant and antibacterial activities. Mater Sci Semicond Process 31:446-454

Suresh J, Pradheesh G, Alexramani V (2018) Green synthesis and characterization of zinc oxide nanoparticle using insulin plant (Costus pictus. D Don ) and investigation of its antimicrobial as well as anticancer activities. Adv Nat Sci Nanosci Nanotechnol 9:015008

Tamuly C, Saikia I, Hazarika M, Bordoloi M, Hussain N, Das MR, Deka K (2015) Bio-derived ZnO nanoflower: a highly efficient catalyst for the synthesis of chalcone derivatives. RSC Adv 5:8604-8608

Tripathi RM, Bhadwal AS, Gupta RK, Singh P, Shrivastav A, Shrivastav BR (2014) ZnO nanoflowers: novel biogenic synthesis and enhanced photocatalytic activity. J Photochem Photobiol B Biol 141:288-295

Varadavenkatesan T, Lyubchik E, Pai S, Pugazhendhi A, Vinayagam R, Selvaraj R (2019) Photocatalytic degradation of Rhodamine $\mathrm{B}$ by zinc oxide nanoparticles synthesized using the leaf extract of Cyanometra ramiflora. J Photochem Photobiol B Biol 199:111621. https://doi.org/10.1016/j.jphotobiol.2019.111621

Varadavenkatesan T, Selvaraj R, Vinayagam R (2020a) Green synthesis of silver nanoparticles using Thunbergia grandiflora flower extract and its catalytic action in reduction of Congo red dye. Mater Today Proc 23:39-42. https://doi.org/10.1016/j.matpr.2019. 05.441

Varadavenkatesan T, Vinayagam R, Selvaraj R (2020b) Green synthesis and structural characterization of silver nanoparticles synthesized using the pod extract of Clitoria ternatea and its application towards dye degradation. Mater Today Proc 23:27-29. https://doi. org/10.1016/j.matpr.2019.04.216

Vinayagam R, Pai S, Varadavenkatesan T (2020a) Structural characterization of green synthesized $\alpha-\mathrm{Fe} 2 \mathrm{O} 3$ nanoparticles using the leaf extract of Spondias dulcis. Surf Interfaces 20:1-9. https:// doi.org/10.1016/j.surfin.2020.100618

Vinayagam R, Selvaraj R, Arivalagan P, Varadavenkatesan T (2020b) Synthesis, characterization and photocatalytic dye degradation capability of Calliandra haematocephala-mediated zinc oxide nanoflowers. J Photochem Photobiol B Biol 203:111760. https:// doi.org/10.1016/j.jphotobiol.2019.111760

Publisher's Note Springer Nature remains neutral with regard to jurisdictional claims in published maps and institutional affiliations. 